\title{
Capturing consumer preferences as requirements for software product lines
}

\author{
Jelena Zdravkovic $\cdot$ Eric-Oluf Svee • \\ Constantinos Giannoulis
}

Received: 14 February 2013/Accepted: 12 October 2013/Published online: 16 November 2013

(c) The Author(s) 2013. This article is published with open access at Springerlink.com

\begin{abstract}
Delivering great consumer experiences in competitive market conditions requires software vendors to move away from traditional modes of thinking to an outside-in perspective, one that shifts their business to becoming consumer-centric. Requirements engineers operating in these conditions thus need new means to both capture real preferences of consumers and then relate them to requirements for software customized in different ways to fit anyone. Additionally, because system development models require inputs that are more concrete than abstract, the indistinct values of consumers need to be classified and formalized. To address this challenge, this study aims to establish a conceptual link between preferences of consumers and system requirements, using software product line (SPL) as a means for systematically accommodating the variations within the preferences. The novelty of this study is a conceptual model of consumer preference, which integrates generic value frameworks from both psychology and marketing, and a method for its transformation to requirements for SPL using a goal-oriented RE framework as the mediator. The presented artifacts are grounded in an empirical study related to the development of a system for online education.
\end{abstract}

\footnotetext{
J. Zdravkovic $(\bowtie) \cdot$ E.-O. Svee · C. Giannoulis

Department of Computer and Systems Sciences, DSV,

Stockholm University, Forum 100, 16440 Kista, Sweden

e-mail: jelenaz@dsv.su.se

E.-O. Svee

e-mail: eric-sve@dsv.su.se

C. Giannoulis

e-mail: constantinos@dsv.su.se
}

Keywords Value - Value modeling - Consumer value $\cdot$ SPL · Goal modeling · Features · Requirements

\section{Introduction}

Business sectors are reshaping rapidly, organizations and consumers are global, and the need for complex software to coordinate it all has become a necessity. Furthermore, the dominance of the Internet, as well as other technology innovations stimulate the growth of such software, offered traditionally as service, thus making it even more available and appealing to consumers. Under these conditions, a software product needs to fit to countless consumers, thus in turn setting tremendous challenges for organizations to develop and support it, while at the same time requiring them to cope with the economic and design sustainability of the product.

Software product line (SPL) addresses the challenges outlined above through the design of software products sharing a common set of features, while at the same time specialized to satisfy the specific needs of a particular market segment. Current research on requirements for SPL sets its primary efforts toward modeling variability in products, cross-cutting concerns, as well as on tool support [1-3]. This is because SPL is a software-driven phenomenon, and there is not sufficient guidance for the development of SPL starting from high-level concerns such as consumer needs and values.

Although how economic values relate to the design of IT systems is an area that has been addressed in business value modeling [4-6], it is not clear how consumer values fit within this context. According to Kotler [7] consumer value plays a crucial role in marketing activities: it is the 
primary driver and the key motivator for the value exchange. This contributes to the argumentation for how the value proposition is able to shape how a business creates differentiated and sustainable value to specific customer segments argued by Kaplan and Norton in [8].

For example, to support different consumer values surrounding convenience, Amazon developed entirely new capabilities to purchase and deliver e-books, something for which its infrastructure for processing and shipping physical goods would not have been designed, leading Amazon to become the leader of both traditional paper and e-book sales online. In health care, electronic health records (EHR), a systematic collection of electronic health information about individual patients or populations, should be shared across different health care settings. Each health care environment functions differently, often in significant ways, and also uses different means of access, thus making it difficult to create a "one-size-fits-all" EHR system. Ideally, such a system would have record standardization, but interfaces and access that can be customized to each provider environment lead many EHR companies to employ vendors to provide such necessary customizations [9]. Moreover, in the telecom business, operators offer the same products and services (such as voice, broadband, TV, and other content) over different access channels (mobile, fixed phone network, fiber-to-home). The content is adjusted to different customer groups based on their various networks; for example, video content will be offered through special video optimizers when delivered to mobile customers, since the mobile network is the one that has lowest capacity and highest production cost per MB of information transferred. In contrast, a "stationary" customer with a fiber-to-home network will be offered higher video and audio quality, in return receiving a better experience on the accessed content.

Although in the above examples the core value exchange remains money for products, the consumer values driving this vary greatly. These examples highlight such variability and show how the success depends on an enterprise's capability to develop its IT systems to efficiently marshal and align its resources to aid in effectively presenting, and delivering upon, its value proposition to consumers.

Consequently, the objective of this study is to present how consumer values can be accommodated in the development of IT systems, by linking them to systems' requirements using a prevalent theory for the design of a collection of similar software products, namely SPL. We propose a method for linking consumer value modeling using the proposed Consumer Preference Meta-Model (CPMM) with Goal-Oriented Requirements Engineering (GORE) approaches, as the latter are acknowledged for effective exploration of intentions and alternatives in requirements [10], and more specifically, for elicitation of variable and common requirements of SPL, as well as for reducing the cost of a specific product within the line [1113]. Using the $i *$ framework [14] as an example for GORE, we also leverage from the existing proposals the ability to link goals to feature models, leading further to the configuration of SPL. A consumer-based approach to collecting requirements for SPL should be able to elevate the alignment between user needs and the final software by producing solutions for a systematic structuring of a diversity of preferences of consumers bundled into a SPL.

The research approach taken in this paper is conceptual and empirical. Concepts used in business modeling, and consumer representation are combined to establish an integrated consumer value framework, which is empirically validated through a study of an online education system. Furthermore, the use of the consumer framework for elicitation of requirements for SPL is argued and demonstrated through the model-based mappings of the consumer framework to a goal framework for RE.

The rest of the paper is organized as follows. Section 2 provides a brief overview of the method proposed in the study. Section 3 presents a discussion on users' values, basic values, and consumer values. In Sect. 4, the consumer preference meta-model is presented, as well as its use in real practice. Section 5 describes how the CPMM is mapped to goal models and further to a feature-based configuration for a SPL. Section 6 provides analysis of results, while Sect. 7 presents the conclusions and directions for future research.

\section{Method overview}

In this section, we provide an overview of the proposed method for utilizing the preferences of consumers to derive the requirements for a line of software products. The method consists of two steps in which different models are constructed (Fig. 1). The objective of the first step is to, by capturing the preferences of the users of a product, produce a consumer preference model that is used as the input to the second step that, using goal-oriented and feature modeling, derives system requirements for a SPL. The identified requirements reflect the different preferences of users of a software system, which by complementing core functional requirements, classify and prioritize additional system requirements as the variations and commonalities of a product line.

Step 1-Preference Capture (Sect. 4). Following a strategy incentive, in this step a future software product line is chosen for development and represented as the central element (value object) in a newly created consumer preference model. Depending on the nature of the value 


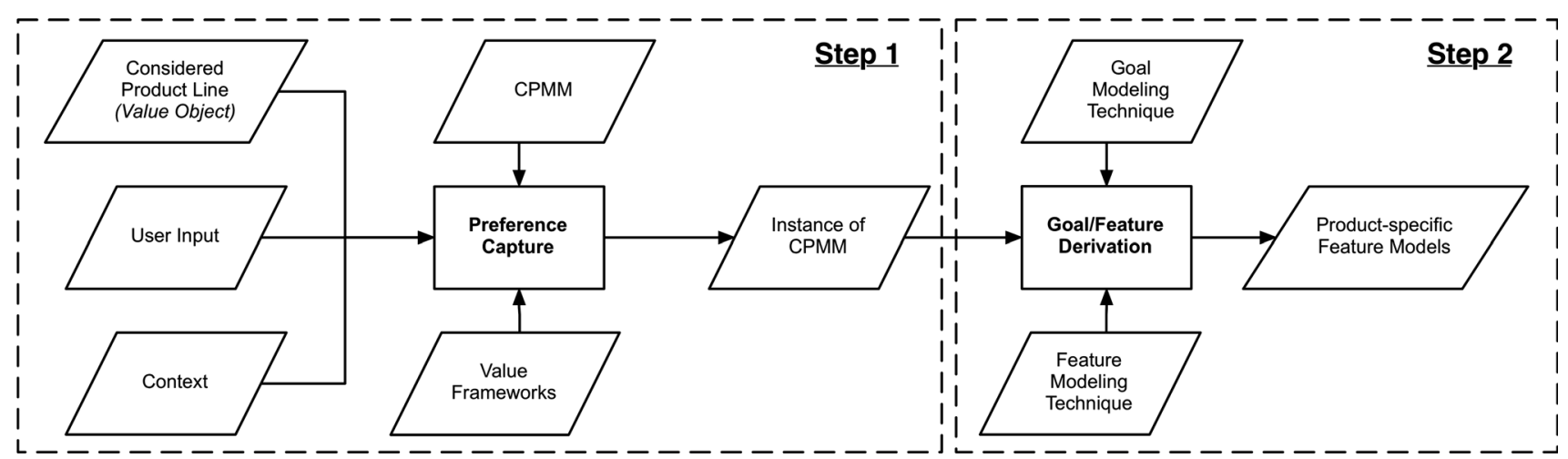

Fig. 1 Method overview

object and of consumers, the latter are classified into distinct segments based on the consumers' demographics and information about the context of use. The desires of segmented consumers for the capabilities of the value object are then collected using one or more relevant user value frameworks. These are captured as qualitative and quantitative measures, first representing desired properties for a product, and the second their priority ranking. The modeling basis in this step is the Consumer Preference MetaModel, CPMM (Sect. 4), with selected user value frameworks (Sect. 3). The outcome of this step is an instance of CPMM, where the possible product configurations in the line are indicated by the consumer's segments, and the qualitative measures elicited in them.

Step 2-Goal/Feature Derivation (Sect. 5). In this step, the information captured in a consumer preference model is used to create goal models to express high-level intentions regarding the products in the line, and feature models describing high-level requirements for the product-specific architectures. The preferred goal modeling technique in this step is $i^{*}[34]$ as it enables the mappings from a value framework [32]. First, a Strategic Dependency i* Model (SDM) is created to present the intentional relationships between the involved actors: the consumer's segments, the product line, and the product line provider. Thereafter, a Strategy Rational $i^{*}$ Model (SRM) is created for each consumer value of interest to reflect the desired internationalities of all consumer segments for a particular value archetype and its elicited qualitative measures. The obtained goal models are then transformed to feature models, whereas each model collects the properties of a single software product in the line, for all the values of interest, which are also prioritized by quantitative measures captured in CPMM in the previous step. The outcome of this step is an early derivation of the product configurations of the line, through the corresponding feature models. They model the preferences of different consumer segments, and as such they complement the core functionality for the line.
In the following, we give an overview of dominant user value frameworks, further used in our method for capturing the preferences of consumers.

\section{Understanding consumer preferences}

In the business-IT alignment discipline, value is most commonly used in an economic sense, to mean an object that can be offered by one actor to another, often where the worth or desirability of something is expressed as an amount of money. A value object (also called a resource) is considered as something of economic value for at least one actor, e.g., a car, a book, Internet access, or a stream of music $[4,15,16]$.

According to [15], a user experience is also recognized as having a value. [17] states that values can be more internal-of psychological and social natures, such as beauty, pleasure, health state, honor, or a feeling of safety. These internal values cannot be directly transferred between actors, and thus, it is not meaningful to talk about legal rights on them, and neither is it possible to transfer any of these resources from one actor to another. None of these proposals from business-IT alignment functions sufficiently to capture and classify explicitly values of consumers, and correcting this constitutes the focus of our work.

The notion of consumer preference is grounded in the work of Powell-Mantel et al. [18], who break down consumer preference into two types: attribute based, involving comparing brands based on specific attributes, and attitude based, involving overall evaluations. The term value is used in this work as a heading for the three primary drivers that cause consumers to seek out goods and services: Human Need, a basic need that must be satisfied (derived from psychology [19]); Basic Value, a belief for what is important in life (derived from psychology, [20]); and Consumer Value, a judgment based on a comparative, 
preferential experience (coming from the marketing sector [21]).

\subsection{Human needs}

Human motivation was explored by Maslow when he proposed his hierarchy of needs [19]. In its final form, there are seven categories. Beginning with those of a basic necessity, and moving further to those that are needed for a more fully realized life, these are as follows: Physiological (breathing, eating, excreting), Safety (security of body, employment, resources, health, property), Love (friendship, family), Esteem (self-esteem, confidence, achievement), Cognitive (knowledge, meaning), Aesthetic (appreciation and search for beauty, balance, and form), and Self-actualization (realizing personal potential, self-fulfillment).

Attempts have been made to concretize Maslow's values, with limited success. With the development of cultural psychology and tools for measuring consumer beliefs, tools based on the hierarchy fell out of favor. However, as a purely conceptual framework, the relevance of Maslow remains a useful construct.

\subsection{Basic values}

Schwartz's Value Theory (SVT) [20] adopts the definition of value from Rokeach [22], summarized as a belief that a specific mode of conduct or end-state is personally or socially preferable to its opposite. Values serve as criteria for judgment, preferences, choices, and decisions as they underlie the person's knowledge, beliefs, and attitudes.

According to Schwartz, all the items found in earlier value theories, including religious and philosophical discussions of values, can be classified into one of the following motivationally distinct Basic Values (Table 1): Power, Universalism, Achievement, Benevolence, Hedonism, Tradition, Stimulation, Conformity, Self-determination, and Security. SVT emphasizes the profound nature of values, but at the same time offers the possibility of a consumer research approach by concretely combining these value structures with an analysis of human motivation. This integrated structure of values can be summarized with two orthogonal dimensions (Table 1): Self-enhancement (the pursuit of self-interests) versus Self-transcendence (concern for the welfare and interest of others); and Openness to Change (independence of action, thought, and feeling, and a readiness for new experiences) versus Conservation (self-restriction, order, and resistance to change).

The values fall within these sections (Table 1) as a continuum, with the motivational goals of the value types in opposing positions around the circle being difficult to pursue simultaneously: The independence sought through
Table 1 Schwartz's basic values as per their classifying dimensions, with examples (italicized)

\begin{tabular}{|c|c|c|c|}
\hline Dimension & Basic value & Dimension & Basic value \\
\hline \multirow[t]{5}{*}{$\begin{array}{l}\text { Openness to } \\
\text { change }\end{array}$} & $\begin{array}{l}\text { Self- } \\
\text { determination } \\
\text { (Creativity, } \\
\text { Freedom) }\end{array}$ & \multirow[t]{5}{*}{$\begin{array}{l}\text { Self- } \\
\text { transcendence }\end{array}$} & $\begin{array}{l}\text { Universalism } \\
\text { (Equality, } \\
\text { Justice) }\end{array}$ \\
\hline & Stimulation & & Benevolence \\
\hline & $\begin{array}{l}\text { (An exciting } \\
\text { life) }\end{array}$ & & (Helpfulness) \\
\hline & Hedonism $^{\mathrm{a}}$ & & Hedonism $^{\mathrm{a}}$ \\
\hline & (Pleasure) & & (Pleasure) \\
\hline \multirow[t]{4}{*}{$\begin{array}{l}\text { Self- } \\
\text { enhancement }\end{array}$} & $\begin{array}{l}\text { Achievement } \\
\text { (Success, } \\
\text { Ambition) }\end{array}$ & \multirow[t]{4}{*}{ Conservation } & $\begin{array}{l}\text { Conformity } \\
\text { (Obedience) }\end{array}$ \\
\hline & Power & & Tradition \\
\hline & $\begin{array}{c}\text { (Authority, } \\
\text { Wealth) }\end{array}$ & & $\begin{array}{l}\text { (Humility, } \\
\text { Devotion) }\end{array}$ \\
\hline & & & $\begin{array}{l}\text { Security } \\
\text { (Social order) }\end{array}$ \\
\hline
\end{tabular}

$\overline{{ }^{a} \text { Hedonism shares elements of both Openness and Self-enhancement }}$ [23]

Self-determination is difficult to achieve within the confines of Security.

Reading from the upper left, Openness to Change (combining Self-determination and Stimulation) opposes Conservation (combining Conformity, Tradition, and Security). These dimensions reflect the conflict between an emphasis on independent thought and action and a preference for change in opposition to self-restriction, preservation of traditional practices, and protecting stability. Moving to the upper right, the dimension Self-Transcendence (combining Universalism and Benevolence) opposes Self-Enhancement (combining Power and Achievement), where in the former one finds acceptance of others as equals, coupled with a concern for their welfare, while in the latter the pursuit of one's own relative success and dominance over others.

Thereafter, Schwartz developed the Value Survey (SVS) to measure these basic values [23]. SVS focuses on a universally applicable method for capturing and describing values across cultures, and it has been applied in numerous places, including business strategy development support [24]. The Value Survey operationalizes the ten basic values with a set of questions such as "It is important to him/her to be rich" or "Having a good time is important to him/her." The answers from the questionnaire can then be converted into a set of numerical results reflecting the weights (importance) of each of the basic values of an individual and can be used directly or visualized via a value structure. 
Later, Schwartz produced the Portrait Values Questionnaire (PVQ) [41] as a simplified version of the SVS by reducing the number of questions substantially from 57 to 21 , making the survey more concrete and less cognitively complex, thus allowing it to be more easily deployed online, as well as more relevant for people with lower literacy. The PVQ includes short verbal portraits of different people, and for each portrait, respondents are asked to compare a person portrayed in each question to themselves by answering, "How much like you is this person?". A 6-point scale is used to capture possible answers with 1 being the strongest and 6 being the weakest. Particularly:

- "Very Much Like Me" (1),

- "Like Me" (2),

- "Somewhat Like Me" (3),

- "A little like me" (4),

- "Not Like Me" (5),

- "Not like me at all" (6).

Each portrait then describes a person's goals, aspirations, or wishes that point implicitly to the importance of a single basic value [41]. These verbal portraits describe each person in terms of what is important to them. Thus, they capture the person's values without explicitly identifying values as the topic of investigation.

Based on both Schwartz's theory and the PVQ, the European Social Survey (ESS) [43] has emerged including 21 items, most from the PVQ and several revised to encompass additional ideas in order to better cover the content of the ten original values. It is this implementation which was utilized in the quantitative study.

\subsection{Consumer values}

Holbrook's Typology of Consumer Value [21] refines the value concept, focusing on those held by individuals during a value exchange, referring to them as consumer values, and classifying them into a Typology of Consumer Values.

According to Holbrook, a consumer value is "an interactive, relativistic preference experience"; interactive entails an interaction between some subject and an object, relativistic refers to consumer values being comparative, preferential refers to consumer values embodying the outcome of an evaluative judgment, and experience refers to consumer values not residing in the product/service acquired but in the consumption experience. Three consumer value dimensions are the basis for his typology: Extrinsic/Intrinsic, Self-oriented/Other-oriented, and Active/Reactive.

Extrinsic is a means/end relationship wherein consumption is prized for its functional, utilitarian ability to serve as a means to accomplish some further purpose, aim, goal, or objective, for example, purchasing from an online
Table 2 Holbrook's typology of consumer values, with examples (italicized)

\begin{tabular}{clll}
\hline & Extrinsic & Intrinsic \\
\hline $\begin{array}{c}\text { Self- } \\
\text { oriented }\end{array}$ & Active & $\begin{array}{c}\text { Efficiency } \\
\text { (convenience) }\end{array}$ & Play (fun) \\
$\begin{array}{c}\text { Other- } \\
\text { oriented }\end{array}$ & Active & $\begin{array}{l}\text { Excellence (quality) } \\
\text { Status (success) }\end{array}$ & $\begin{array}{c}\text { Aesthetics (beauty) } \\
\text { Ethics (virtue, } \\
\text { justice) } \\
\text { Spirituality (faith, } \\
\text { sacred) }\end{array}$ \\
\hline
\end{tabular}

bookseller solely because it has the lowest prices. Intrinsic occurs when some consumption experience is appreciated as an end in itself-for its own sake, such as choosing to shop at a book store rather than an online retailer due to its comfortable reading room and pleasant ambience.

Self-oriented refers to occasions where some aspect of consumption is cherished, either selfishly or prudently, for the individual's sake; an efficient online book store saves time and effort when purchasing books. Other-oriented refers to occasions where the consumption experience or the product on which it depends is valued by others, either beyond the subject, for its own sake, for how they react to it, or for the effect it has on them. A consumer may be driven to buy a book from a local book store instead of Amazon in order to support the local economy.

Active entails a physical or mental manipulation of some tangible or intangible object, involving things done by a consumer to or with a product as part of some consumption experience: The experience of reading from a paper book versus an electronic one has great appeal to many people. Reactive results from apprehending, appreciating, admiring, or otherwise responding to an object, when the object acts upon the subject. Similar to the example given for intrinsic, the dream of reading in a book-filled space also be reactive, when the primary force behind the consumption experience is the object of consumption (the book) and not the subject (the consumer).

Based on these three dimensions, Holbrook's Typology of Consumer Values identifies eight archetypes that represent distinct types of value in the consumption experience (Table 2): Efficiency, Excellence, Status, Esteem, Play, Aesthetics, Ethics, and Spirituality.

\section{Capturing consumer preference}

The meta-model presented in this section provides both the theoretical and methodological foundations for consumeraware requirements engineering. An initial version of the meta-model is proposed in [25], which in the following sections has been elaborated and improved upon relevant related research and a comprehensive empirical study. 


\subsection{Consumer preference meta-model (CPMM)}

Our conceptualization of consumer preferences includes three perspectives-business modeling, addressing the core concepts related to the exchange of a product line of concern; consumer modeling, where peoples' preferences about the product line are modeled according to existing theories; and segment modeling, which is designed to enable profiling of the consumer.

\subsubsection{Business modeling}

The purpose of a business model is to describe the transfer of economic value between involved actors-economically independent entities [4-6]. Using business modeling for our consumer-oriented conceptualization, leads in Fig. 2 to capturing two main Actors: a Provider and a Consumer. The exchange between them assumes transfer of the Value Object, characterizing a future software product line, such as online education system.

\subsubsection{Consumer modeling}

Consumer is a role representing a group of people in the consideration for the evaluation of the Value Object based on individual preferences. In Sect. 2, we have reported prevalent frameworks addressing people's preferencesHuman Needs [19], Basic Values [20], and Consumer
Values [21] all of which are seen as driving consumers' desires to participate in the exchange process, i.e., as Consumer Driver, which should be satisfied through a consumption experience of the Value Object. Needs of Maslow and Basic Values of Schwartz are generic drivers of human actions, while Holbrook's value framework (Consumer Value) concerns preferences on the products for consuming, i.e., Value Object specifically. Each of these frameworks, as well as any other framework taken into conceptualization in Fig. 2, categorizes its values by consumers as a Measure, which can be Quantitative Measure and/or Qualitative Measure. Quantitative Measure is used for storing the numerical rankings or importance of the values as perceived by consumers, such as for example in the Basic Value framework for motivations for an individual or a group of persons. Qualitative Measure is used to record refinements (examples) of archetypes of values provided by a value framework. Additionally, different frameworks (Consumer Driver) could be used integrated to combine their values or measures, and for that the Mapping association class is used.

\subsubsection{Segment modeling}

Segment characterizes a subclass of Consumer, distinguished using the information on the Context of Use for a product, and the Demographics of consumers. It enables to identify the Measures as preferred by a group of consumers
Fig. 2 Consumer Preference Meta-Model (CPMM)

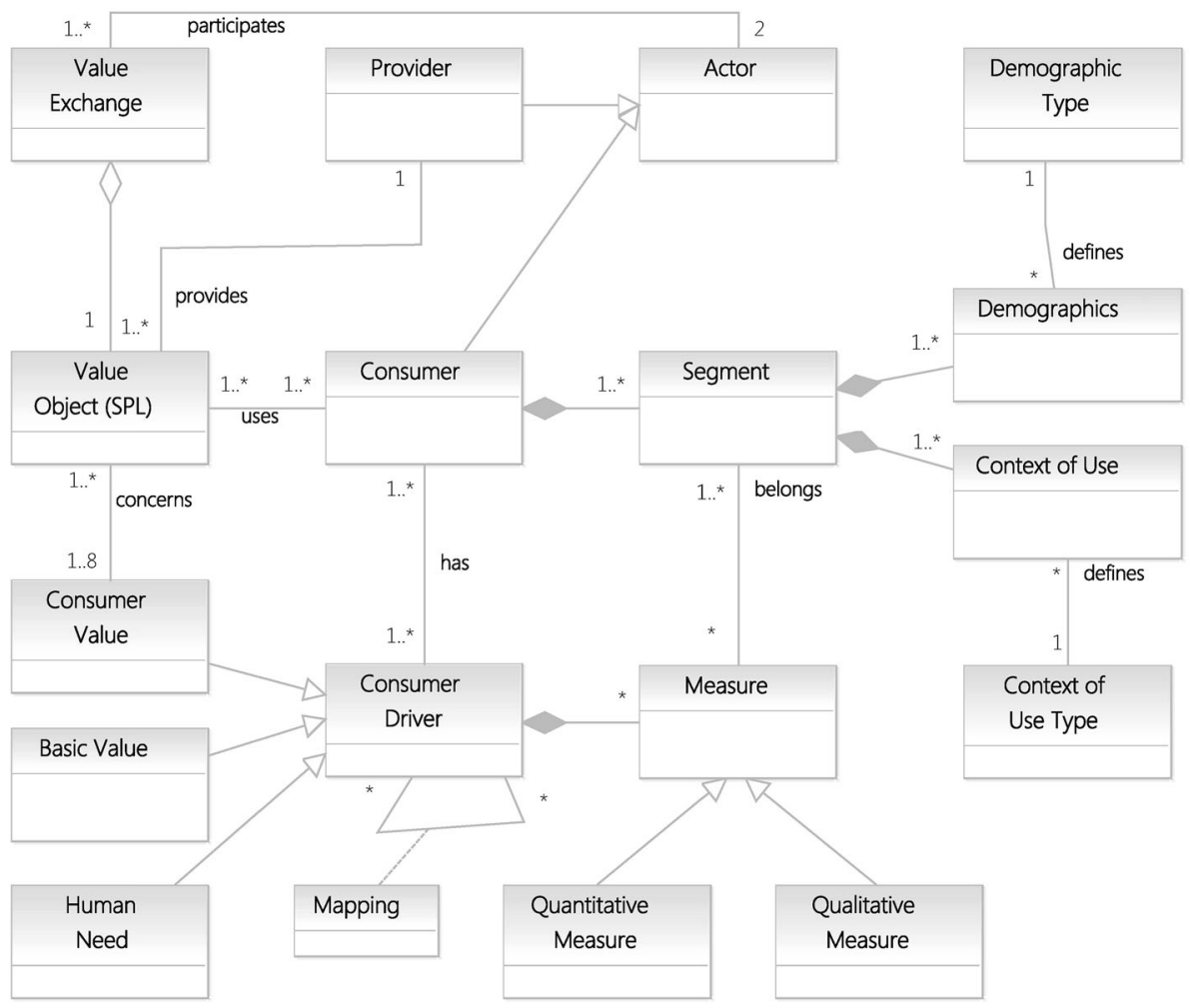


of interest, or conversely, similar preferences for Measures can be used to identify the segments of consumers. Context of Use captures the information characterizing the setting and circumstances under which a Value Object will be used by a Segment. This property reflects an individual's context, as discussed in [26, 27], where consumer's location, environment, time, and identity are considered as the main context elements. In our modeling view, identity is separately covered by Demographics, encompassing segment's characteristics, such as age, ethnicity, education, and similar.

\subsection{Capturing consumer preferences using CPMM}

Using CPMM from Fig. 2, a consumer preference model can be created, starting with an indication of the product of interest (Value Object) and a relevant population of consumers, represented in the model by Consumer. In some situations, both the product and the consumer are evident, while at certain times a business strategy analysis is first applied in the organization (Provider), to reveal the products of interest and its foreseen users [28].

Once the consumer's population is decided, the next step is to collect the preferences of the population using a Consumer Driver (Fig. 2), i.e., a value framework. In Sect. 3 , we have described three established value frameworks, where Maslow's (Human Needs) although widely known has a disadvantage of lacking proven instruments for relating the importance of the needs among each other. In contrast to that, Schwartz's Basic Values can be "weighted" using the SVS, or PVQ survey tools as explained in Sect. 3.2, and stored as Quantitative Measures in CPMM. This in our view makes this framework a worthy candidate to use for the elicitation of the preferences in Consumer Drivers. Evidence for this theoretical structure has been found in samples from 67 nations [20, 23]. It points to the broad underlying motivations that may constitute a universal principle that organizes value systems. People may differ substantially in the importance they attribute to values that comprise the ten basic values, but the same structure of motivational oppositions and compatibilities apparently organizes their values. This integrated motivational structure of relations between values makes it possible to study how whole systems of values, rather than single values, relate to other variables.

However, having in mind the profiling of the consumer role in the domain of goods and service offering, Holbrook's Consumer Value classification also becomes important as it classifies and describes the values from a more specific perspective-those of consumers. Following this argumentation, we consider an integrated use of Basic Values to capture the preferences of the consumer population in accordance to their universal motivations (such as
Power or Security), and Consumer Values to elicit concrete and tangible desires for a product (Qualitative Measures in Fig. 2) of interest (such as "gaming" or "exciting exercises" as a part of the value Play). To achieve this integration, it is necessary to map the two value perspectives to an applicable framework (Mapping in Fig. 2).

In the following, we outline the mappings; to understand their meanings, it is necessary to recall from Sects. 3.2 and 3.3 both the dimensions that Holbrook uses to define his archetypical consumer values, as well as those of Schwartz. Table 3 summarizes the correspondences among them.

As an example in Table 3, Schwartz's Openness to Change (independence of action, thought, and feeling, and a readiness for new experiences) maps to Self-Oriented (the value exchange is cherished for the individual's sake), Active (entailing a direct use of an object), and Intrinsic (consumption experience is appreciated as an end in itself) dimension in Holbrook's framework.

Utilizing the relationships from Table 3, the final mappings from the two groups of the values are derived and presented in Table 4 below.

As an illustration of the results in Table 4, we consider the mapping of Stimulation basic value to Play consumer value. Holbrook's Play is a self-oriented experience,

Table 3 Mapping Schwartz's Basic Value Dimensions and Holbrook's Consumer Value Dimensions

\begin{tabular}{ll}
\hline Schwartz's Value Dimensions & Holbrook's Value Dimensions \\
\hline Openness to change & Self-oriented, Active, Intrinsic \\
Conservation & Self-oriented, Active, Extrinsic \\
Self-transcendence & Other-oriented, Active, Intrinsic \\
& Other-oriented, Reactive, Intrinsic \\
Self-enhancement & Self-oriented, Reactive, Extrinsic \\
& Self-oriented, Reactive, Intrinsic
\end{tabular}

Table 4 Mapping Schwartz's Basic Values to Holbrook's Consumer Values [29]

\begin{tabular}{|c|c|c|c|}
\hline & & Extrinsic & Intrinsic \\
\hline \multirow[t]{2}{*}{$\begin{array}{l}\text { Self- } \\
\text { oriented }\end{array}$} & Active & $\begin{array}{l}\text { Efficiency } \\
\text { (Conformity, } \\
\text { Security) }\end{array}$ & $\begin{array}{l}\text { Play } \\
\text { (Self-determination, } \\
\text { Stimulation) }\end{array}$ \\
\hline & Reactive & $\begin{array}{l}\text { Excellence } \\
\text { (Achievement) }\end{array}$ & $\begin{array}{l}\text { Aesthetics } \\
\text { (Hedonism) }\end{array}$ \\
\hline \multirow[t]{2}{*}{$\begin{array}{l}\text { Other- } \\
\text { oriented }\end{array}$} & Active & $\begin{array}{l}\text { Status } \\
\text { (Power) }\end{array}$ & $\begin{array}{l}\text { Ethics } \\
\text { (Universalism) }\end{array}$ \\
\hline & Reactive & $\begin{array}{l}\text { Esteem } \\
\text { (Power, } \\
\text { Achievement) }\end{array}$ & $\begin{array}{l}\text { Spirituality } \\
\text { (Benevolence, Tradition) }\end{array}$ \\
\hline
\end{tabular}

Holbrook's values are indicated by bolded Roman text, while Schwartz's values are italicized 
actively sought and enjoyed for its own sake, and as such, typically involves having fun. Schwartz's Stimulation, belonging to the dimension "Openness to Change" (Table 3) is based on excitement and novelty, and as such it is directly experienced is related to Play via Holbrook's Self-Oriented, Intrinsic, and Active dimensions. For the further details of the mappings, the reader is referred to [29].

Having the mappings described above, it becomes possible to use a consumer preference model in the way to (a) prioritize the preference of users using the Quantitative Measure instrument available for the Basic Value framework and (b) collect their tangible properties by Qualitative Measures of Holbrook's framework, which may be then considered for a transformation to the requirements for a system. As explained in the previous section, by analyzing the Demographics and Context of Use, it becomes possible to group the collected Measures in order to derive similar Consumer's groups in the form of Segments, i.e., sharing same value dominance.

\subsection{Empirical study: online education system}

One of the greatest challenges in online education concerns creating courseware that will be appealing to diverse student audiences. Many argue that, for online systems to be successful in encouraging students' attention and learning, one of the crucial factors is to design such systems to support both intrinsic and extrinsic motivations/values of students [30, 31].

Thus, for the purpose of this research, we have performed an empirical study in two parts:

1. As a first step, we administered the European Social Survey (ESS), an implementation of the European Social Survey (a form of Schwartz's Portrait Value Questionnaire (PVQ) designed by Schwartz for online use (Sect. 3.2) to capture the preferences (Quantitative Measures of Basic Values) of a large sample of students, representing Consumer in CPMM) (Fig. 2).

2. As second step, a smaller representative sample was interviewed to elicit their preferences regarding online education system (Value Object), in the scope of Consumer Values, and specifically their Qualitative Measures (CPMM, Fig. 2).

In the following, the details of the two study parts are presented:

1. The ESS has been used to capture the values of applicants to university programs beginning in the autumn of 2012 at Swedish universities. The Swedish Agency for Higher Education Services (Verket för högskoleservice), the authority coordinating the admission process for higher education courses and programs in Sweden, has been used as a data source providing a simple random sample from these applicants. The primary portion of the survey consisted of the 20 questions that constitute the ESS which, via statements tailored to each participant's gender, captures basic values. A small set of the questions to capture segments of students, by capturing information on demographics, and context of use (see Fig. 2), such as person's age, cultural origin, devices used for connecting to the Internet, and others, was appended to the ESS. Surveys were available in either English or Swedish and were emailed requests for participation. Results from 218 participants (91 men, 127 women) are ranked in Fig. 3. In the scales $1-6$, weights closer to 1 indicate a strong personal identification with the value, while those approaching 6 indicate a lack thereof. These scores are averaged, as per Schwartz's instructions [42].

For the convenience of the illustrations in this study, we have presented the survey's results along a single segment/ demographics variable, namely "academic experience", within which "Non-Master" indicates undergraduate students, while "Master" indicates those people who already have a master's degree. Thus, this classification distinguishes the students with no/modest experience with incampus and online education, from those whose experience is substantially richer. Table 5 summarizes the results of the survey for both the population's segments, displaying the preference (Quantitative Measure in CPMM) of the two segments of students (Consumer) for Basic Values.

Several key differences between the aggregated value profiles bear mentioning. First, the priorities of the first and third values are reversed between each of the populations, where Universalism is the most important to non-master's students and Self-determination is the most important to master's students. Another significant finding is the value hedonism, under which the system's appearance would be taken into account (e.g., user interface). The difference between the two populations' Schwartz values is .456 and which in the PVQ's 6-point scale is a significant enough difference that it could have an impact on how resources are directed during system development; if the students are more concerned with security than appearance, successful adoption of the system depends upon resources being directed toward the security aspect-the value which would have the highest likelihood of motivating the individuals to accept the system-rather than on another less important priority. Following the mappings between Schwartz's and Holbrook's value frameworks explained in the previous section, it has become possible to reflect the obtained preferences further to the consumer domain, i.e., to Consumer Values (indicated also in Table 5).

2. The second part of the study involved profiling Consumer Values through individual interviews, where students were asked to describe their preferences for an 

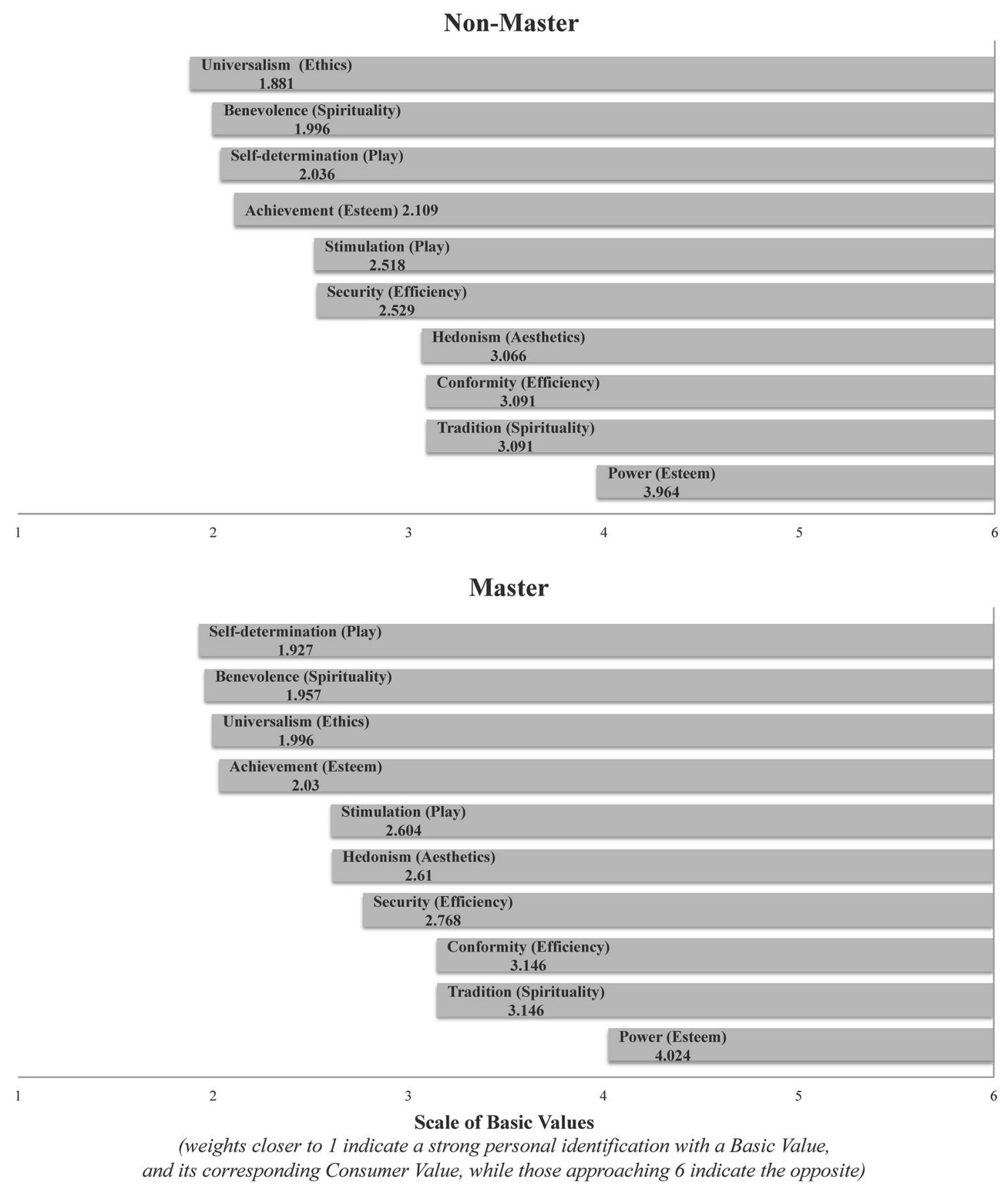

Fig. 3 Results on basic values for Swedish university applicants from study's ESS implementation

online education system in terms of each of the eight Holbrook's value archetypes. For the interview, the investigators had developed a series of questions-eight in total-that were each based on a value from Holbrook's Typology. The participants were asked to respond to these, and the investigators took written notes and audio recordings. Each interview lasted $45-60 \mathrm{~min}$. The results of the 18 interviews, including the representatives from both the Non-Master and Master segments, have been analyzed and stored as $\sim 220$ Qualitative Measures (CPMM, Fig. 2). An example of the differences between QM of the two populations can be seen in their understanding of the value Universalism/Ethics. Not only is the value prioritized differently (the non-master's students consider it their most important value, whereas for master's students it is their third, see Fig. 3), but the means they use to express it are quite different. Master's students are more inclined to see ethical lapses as something that the university should 
manage, such as "communication o university values/policies” (Fig. 5). In contra poise, non-master's students prefer that the matter be managed on an individual level (such as "identity verification on exams" or "individual evaluation" measures, see Fig. 5). Furthermore, these values mirror the differences between the two populations interest in Self-determination/Play, with one group being more interested in individual conformity (master's students) than the other.

\section{Deriving goals and features as requirements for SPL}

Once a product is examined for preferred capabilities by a consumer population using the Consumer Preference MetaModel, the collected information needs to be transformed further to requirements models, with the purpose to configure a software product line (SPL).

As shown in the previous section, consumer drivers in CPMM (Fig. 2) are derived using value-based frameworks for individuals. These drivers are related to a product of interest (Value Object) by emphasizing its desired properties, although in different ways. In early phases of requirements engineering, business models describing constellations of actors, provisioning and use of a product, or a group of related products, are closely related to goal frameworks, which can be used to elicit high-level system requirements for the product(s) $[32,33]$. In the SPL discipline, goal-orientation is also recognized as an affirmative way to elicit variable and common system requirements by analyzing goals of stakeholders [1,11-13].

Based on this argumentation, in this section we present a goal-based method for linking the preferences of consumers with requirements for software product lines. At first, we propose the mappings from CPMM to an established RE goal-oriented framework, namely i* [14]; second, we derive product-specific feature models of SPL from i* goal models. We illustrate the method through our empirical study by mapping the values, as elicited by a student population, to an $i^{*}$ model, and further, to feature models for SPL for online education.

\subsection{Mapping Consumer Preference Meta-Model to i* framework}

CPMM is a consumer-centric extension of a value-based business model, showing how a product intended for exchange between a provider and consumers is desired from consumer's perspective. On the other side, the $i^{*}$ framework is meant for capturing intentions of a group of dependent actors, such as stakeholders in a requirements engineering process. $i^{*}$ provides a rich modeling notation in this context [34].
In this section, we propose the use of $i^{*}$ based on CPMM through mappings shown in Table 6 and through a set of accompanying guidelines. Relevant to this study, an $i^{*}$ SDM (Strategic Dependency Model) diagram is used to model all actors (student segments, the online education system, and the university) as well as their interdependencies (Fig. 5), while i* SRM (Strategic Rationale Models) diagrams are used to model internal actor's interests and intentions (Figs. 5, 6). Table 5 presents intentional elements of $i^{*}$ used in the mappings of Table 6. Other elements of $i^{*}$ used are explained in line with the proposed guidelines.

Based on [32], where the mappings between $e^{3}$ business value model and $i^{*}$ goal framework are defined, we propose the mappings of our consumer-centric value metamodel CPMM, to $i^{*}$ as shown in Table 6.

Table 5 Elements of $i^{*}$ (see [34]) relevant to CPMM

\begin{tabular}{ll}
\hline i* elements & Explanation from [34] \\
\hline Actor & An entity carrying out actions to achieve goals \\
Agent & $\begin{array}{c}\text { An actor with concrete, physical manifestations, } \\
\text { such as a human individual or artificial } \\
\text { (hardware/software) agents }\end{array}$ \\
$\begin{array}{l}\text { Resource } \\
\text { dependency }\end{array}$ & $\begin{array}{l}\text { A directed dependency between two actors for a } \\
\text { resource (physical or informational) to be } \\
\text { available }\end{array}$ \\
$\begin{array}{c}\text { Soft-goal } \\
\text { dependency }\end{array}$ & $\begin{array}{l}\text { A directed dependency between two actors to } \\
\text { soalisfied a soft-goal }\end{array}$ \\
& $\begin{array}{l}\text { An intentional desire of an actor with clear-cut } \\
\text { satisfaction criteria (how the goal is to be } \\
\text { satisfied is not described by the goal). }\end{array}$ \\
& $\begin{array}{l}\text { Satisfaction of goals is described through means- } \\
\text { end links from tasks }\end{array}$ \\
& A condition about the world an actor holds to be \\
true. Beliefs can affect other elements in the \\
model via contribution links, and may affect the \\
effect of an element on another, or can have a \\
direct effect on soft-goals
\end{tabular}

Soft-goal An intentional desire of an actor with no clear-cut satisfaction criteria. Contribution links from other elements describe how soft-goals are satisfied. An intentional desire of an actor with no clear-cut satisfaction criteria. Therefore, a softgoal cannot be satisfied but can only be satisfied and thus, contribution links from other elements describe how soft-goals are satisfied. However, in this paper, the naming convention followed in soft-goals across all figures states "... be satisfied" to avoid introducing more noncommonly used terms

Resource An element, physical or informational with no specifics on how the entity will be achieved

Task An element capturing the specifics of some action performed in a particular way but without a complete specification of the steps required to execute it 
Table 6 Mapping elements of Consumer Preference Meta-Model to i* framework

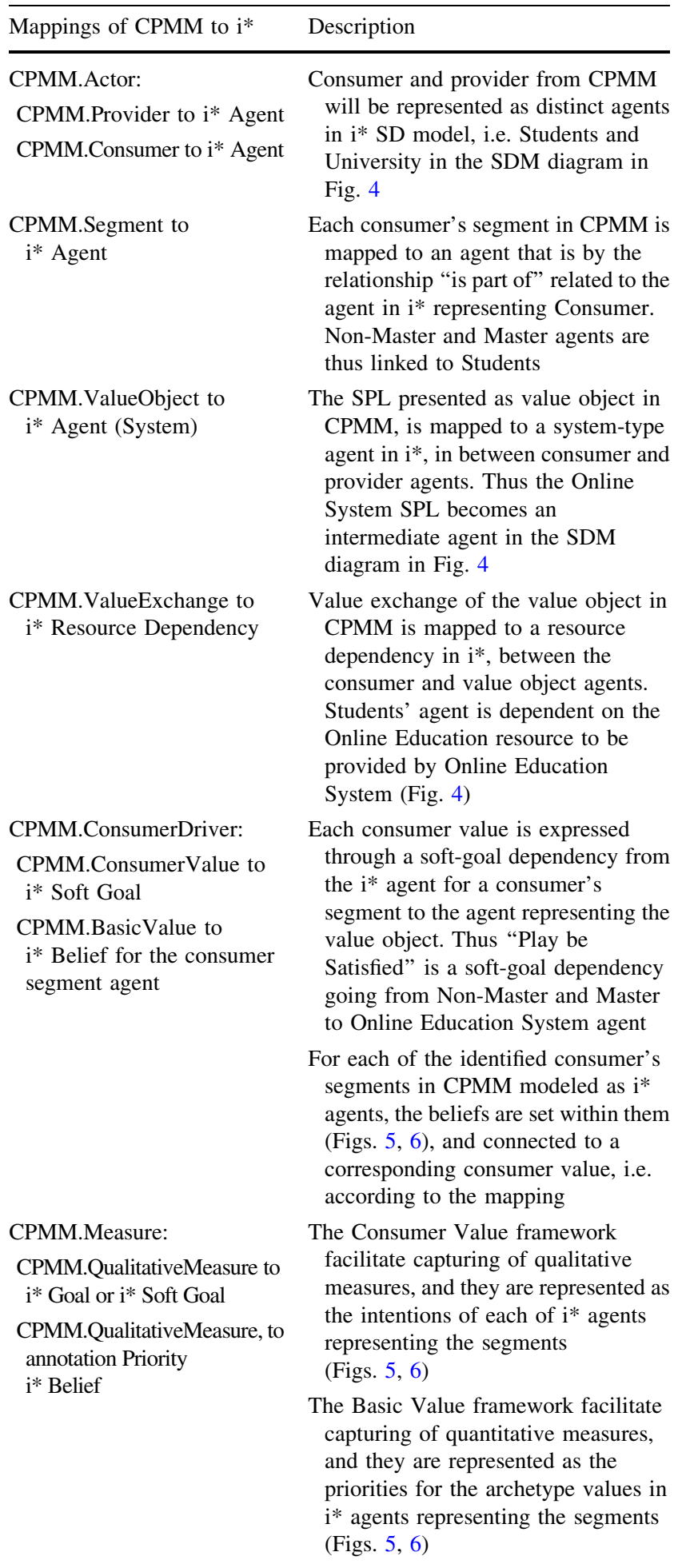

The aforementioned mappings have been applied within the scope of our empirical study to build $i^{*}$ SDM diagram in Fig. 4 and i* SRM diagrams presented in Figs. 5 and 6.
For the SRM diagram, we present two parts of the complete diagram where the top basic values of each segment are elaborated. Top values are identified through the numbers used to annotate beliefs of agents: Universalism for non-master's students and Self-determination for master's students. These numbers are used to carry the priority of weight of the segments' basic values as this is derived from CPMM and the results of our empirical study on these segments. Therefore, the SRM diagrams are focused on the corresponding consumer values of these top two basic values, based on the mappings of Table 6 .

The corresponding consumer value for Universalism is Ethics, and thus one SRM diagram is focused on the softgoal dependency "Ethics be Satisfied" (Fig. 5). The corresponding consumer value for Self-determination is Play, and thus the other SRM diagram is focused on the soft-goal dependency "Play be Satisfied" (presented in Fig. 6). Also, the SRM diagrams contain intentions for the core (domain) functionality of the online education system derived from the real-life setting of our example. These are exemplified with the goals "Online Examination be Supported," "Course Material be Available," and "Communication between Participants be Supported" (Figs. 5, 6). To distinguish which intentional elements are expressed by which segment we are following a consistent coloring scheme in the SRM diagrams. Darkly shaded elements express NonMaster students, lightly shaded elements express Master students, and non-shaded elements are those commonly expressed by both segments.

Within each agent, the belief Universalism is associated with the soft-goal "Ethics be Satisfied" (Fig. 4) and the belief Self-determination is associated with the Soft-Goal "Play be Satisfied" (Fig. 5). Within the online education system, actor each soft-goal coming from the soft-goal dependency expresses the students' consumer value needed to be satisfied by the online education system. Therefore, the qualitative measures of CPMM are used to elaborate how these consumer soft-goals should be satisfied through other soft-goals and goals. Tasks and resources are omitted, as they are too specific to capture the intentionality needed to satisfied the consumer value soft-goals.

Guideline 1: Use answers to leading questions for each of the consumer values to identify intentions and preferences. Leading questions for each consumer value make use of examples for value archetype (e.g., fun for Play: How would you find fun in using an online education system?). Answers to such leading questions provide intentions and preferences, which can be expressed through goals and/or soft-goals affecting consumer value, and can be further elaborated.

The outcome of this guideline is a set of goals and/or soft-goals associated with the consumer value soft-goal 


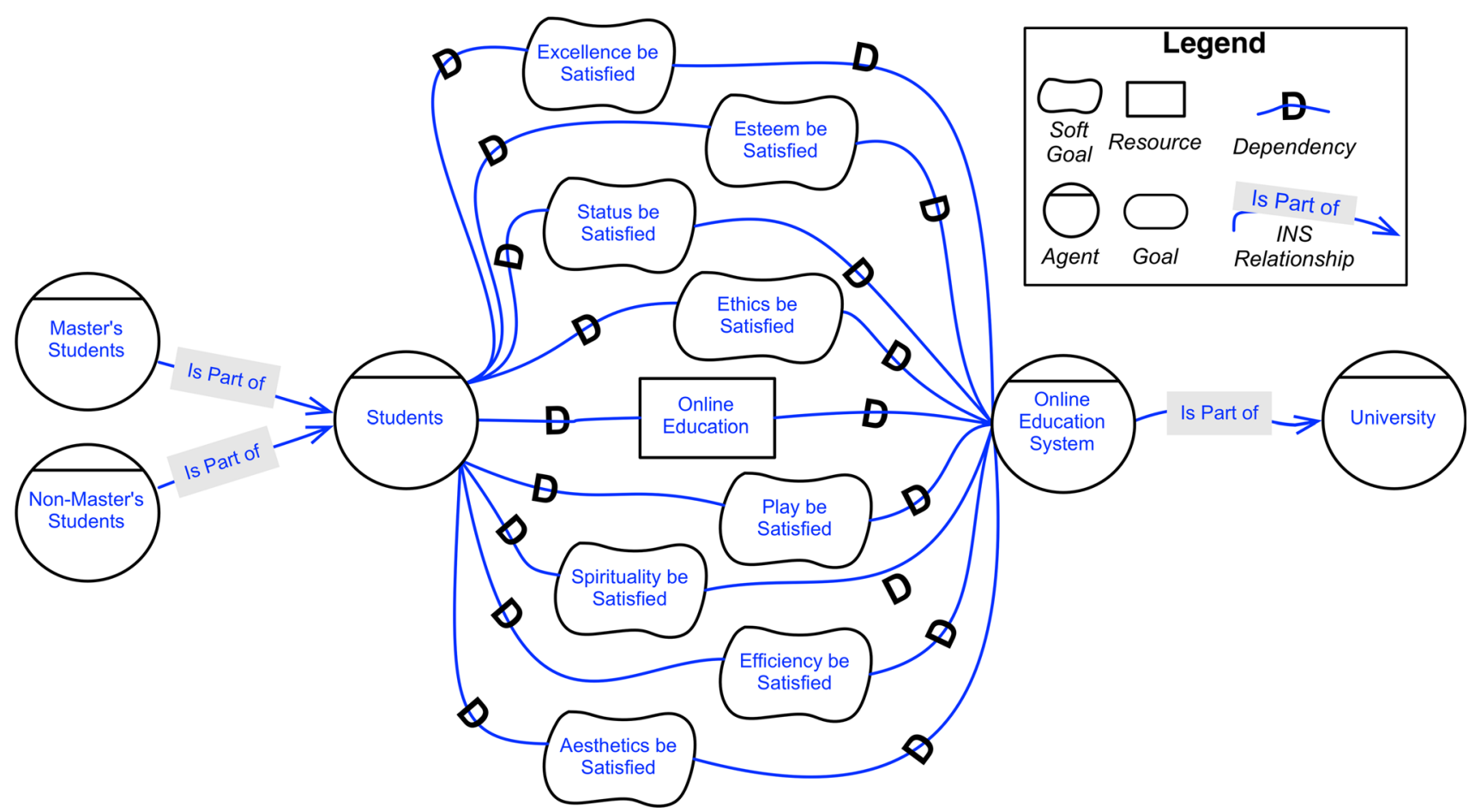

Fig. 4 SD diagram for online education

directly. Thus, intentional elements directly associated with the consumer value soft-goal are derived from answers on leading questions. For example, Ethics is directly associated with soft-goals "Cheating be Prevented", "Proper Rules of Conduct be Established", "System be trusted" (Fig. 5), and Play is directly associated with soft-goals "System be Fun to Use", "System be Interactive" (Fig. 6).

Guideline 2: Elaborate on the intentions affecting the elements derived from Guideline 1. Based on the qualitative measures of CPMM used to record refinements of the generic sets of values as expressed by consumers, intentions of consumers can be identified and expressed either as a soft-goal or as a goal.

The outcome of this guideline is a complete set of goals and/or soft-goals expressing consumers' intentions of how the system can satisfied their consumer values.

Guideline 3: Group elements in respect to the goals/softgoals derived from Guideline 1. Goals and soft-goals derived from Guideline 2 are grouped with respect to the elements identified from Guideline 1, since the latter are derived directly from the leading questions about consumer values. This grouping will enhance the identification of appropriate contribution links between goals and sub-goals. Issues to consider include:

1. If there are goals/sub-goals not relevant to those coming from Guideline 1, then one needs to identify/ interpret how such goals/soft-goals can be related to the consumer value soft-goal, which will allow for an appropriate type contribution link (in Guideline 4).

2. If there are goals/soft-goals that appear to be more general than goals/soft-goals coming from the leading questions, then one should re-assess the grouping.

The outcome of this guideline is a complete set of grouped goals/soft-goals forming a hierarchical structure from the most general one (consumer value soft-goal) to concrete ones (ending leaf goals).

Guideline 4: Identify contribution links between intentional elements derived during the previous steps. In accordance with the $i^{*}$ guide, soft-goals should be ending leaves of a goal model [34], and therefore, soft-goals are decomposed through contribution links either further to other soft-goals or to goals. The ending leaves of this decomposition are goals as they can only be further decomposed into $i^{*}$ tasks, which are specific. The types of contribution links identified in our example (Figs. 5, 6) are motivated as follows:

1. Soft-goals directly contributing to the consumer value soft-goal are associated through an And Contribution Link because they altogether express the complete set of intentions based on the answers of the leading questions. An And Contribution Link implies that the parent is satisfied if all offspring are satisfied [34]. 


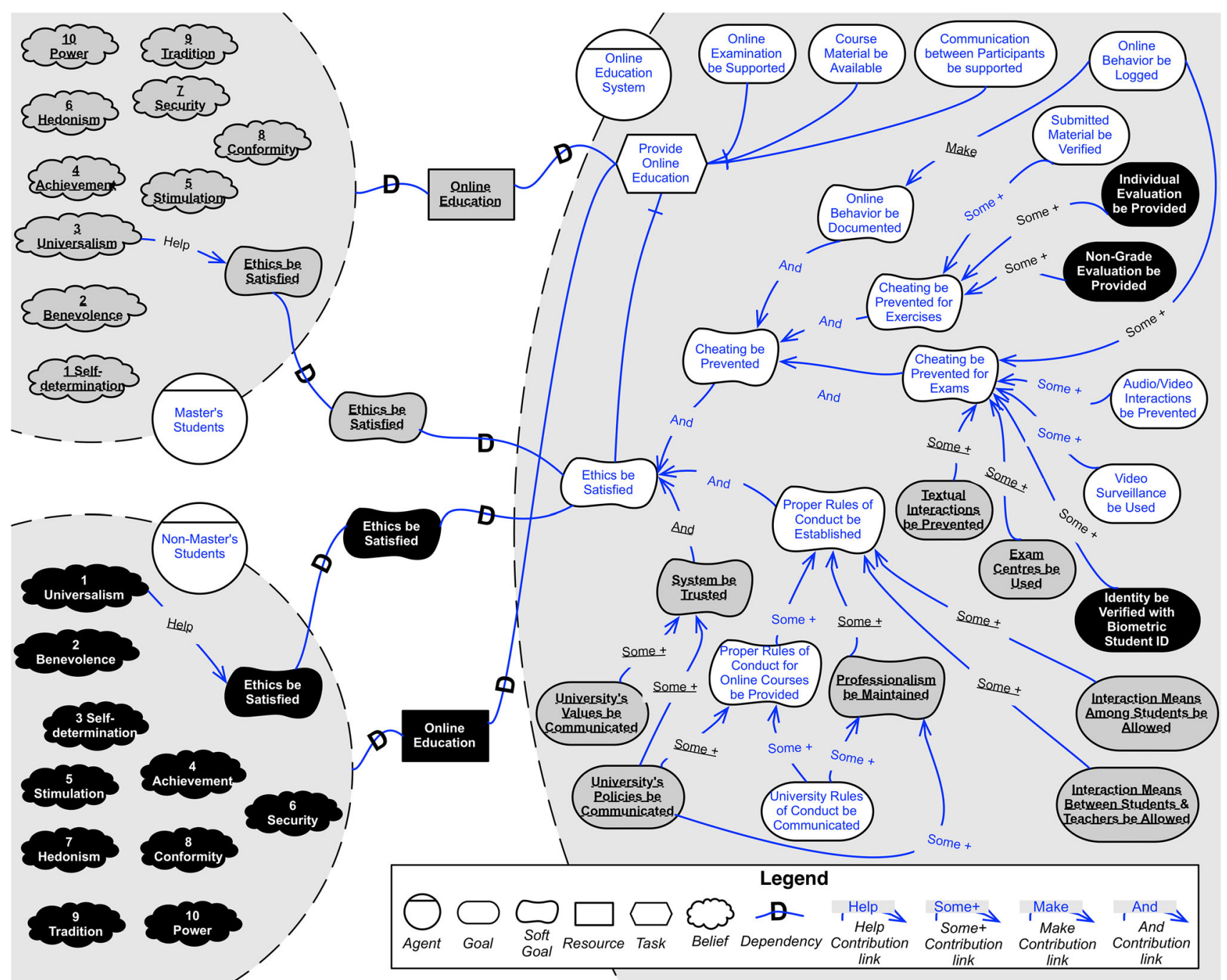

Fig. 5 SR diagram for Universalism aka Ethics

2. If there is only one goal/soft-goal contributing to another (from the same segment), then the association used is Make Contribution Link because it indicates a positive contribution enough to satisfied the soft-goal [34] (e.g., from goal "Layout be Customizable" to soft-goal "Good Layout be Designed" in Fig. 6).

3. If there is more than one goal/soft-goal contributing to another the association used is Some + Contribution Link because it indicates some positive contribution to satisfied a soft-goal but whose strength is not explicit [34]. Therefore, using the Some + indicates that the sub-elements positively contribute to the soft-goal be satisfied but in an unknown strength (Figs. 5, 6).

After all contribution types have been identified, every group has been assess against the goal/soft-goals contributing to the consumer value soft-goal, since each group must have at least one goal/soft-goal contributing to the consumer value soft-goal.
The outcome of this guideline is a set complete set of goals and soft-goals associated with contribution links having only goals as ending leaves as shown in the SR diagrams presented in Figs. 5 and 6.

Figures 5 and 6 are parts of a complete i* SR model for the online education system and constitute input to the process for identifying domain and application features for the SPL, which is presented in the following section.

\subsection{Identifying features and requirements for SPL}

Once an i* SR model is obtained from a CPMM, the "system" is the actor representing future SPL. To link the $i^{*}$ SR model with a configuration for SPL, the theory of feature modeling is applied, where features are used as the basis for analyzing and representing commonality and variability of systems in a solution domain $[35,36]$. 


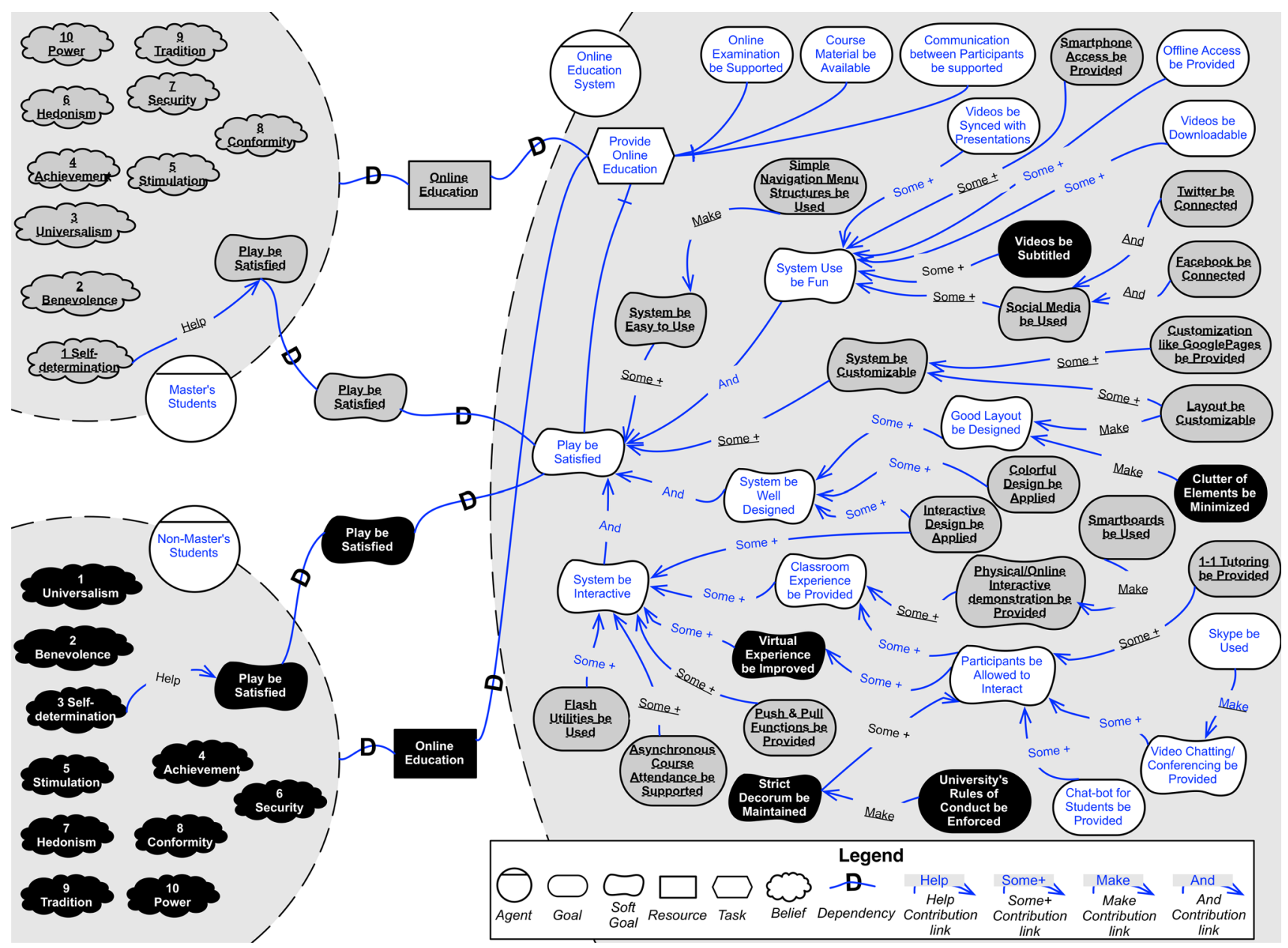

Fig. 6 SR diagram for Self-determination aka Play

For the elaboration of the requirements for SPL from an i* SRM diagram using features, the proposal concerning feature configuration based on stakeholder goals [11] is adopted because it is based on the intentional variability of goals coming the variation of different stakeholders' goals. The reason for choosing this proposal stems from the fact that in the prior steps (Sect. 5.1) intentionality of consumer preference has been expressed in $i^{*}$ in the form of a hierarchical structure of goals and soft-goals under a generic consumer value soft-goal based on the mappings of CPMM to $i^{*}$. Motivation for this choice has been based on the fact that consumer values are qualitative in nature and thus cannot be explicitly satisfied; rather, specifics of their satisfaction cannot be necessarily derived solely from values. This makes understandable why proposals such the G2SPL [37] is not suitable to derive feature models-the basis for such derivation under G2SPL are i* Tasks and Resources, in line with PRiM (Process Reengineering i* Method) [38], and not goals. Liaskos et al. [50] have proposed a goal-based framework about preference variability on requirements which is focused on stakeholders' preference goals in terms of quality desires and temporal preferences. While this work also acknowledges the influence of context when setting/defining priorities, it does not relate to feature models for SPL, and in terms of priorities the approach makes use of a given relative importance among preference goals. Priorities coming from CPMM could be input to this approach, however, not within the context of SPL.

With respect to this proposal, goals are mapped to system features and soft-goals are used to generate qualitative constraints for the feature model. Within the scope of our work, features derived from consumer values are considered as optional with respect to the core (domain) functionality of the system. However, once a consumer value is selected for consideration in a system, all derived features from this consumer value become mandatory, as they are required to satisfied the consumer value soft-goals.

In our example scenario, the mapping of goals into features and the derivation of feature constraints from softgoals is summarized in Figs. 7 and 8, where features for each of the two segments are presented. Features derived from goals unique to Non-Masters Students are darkly 


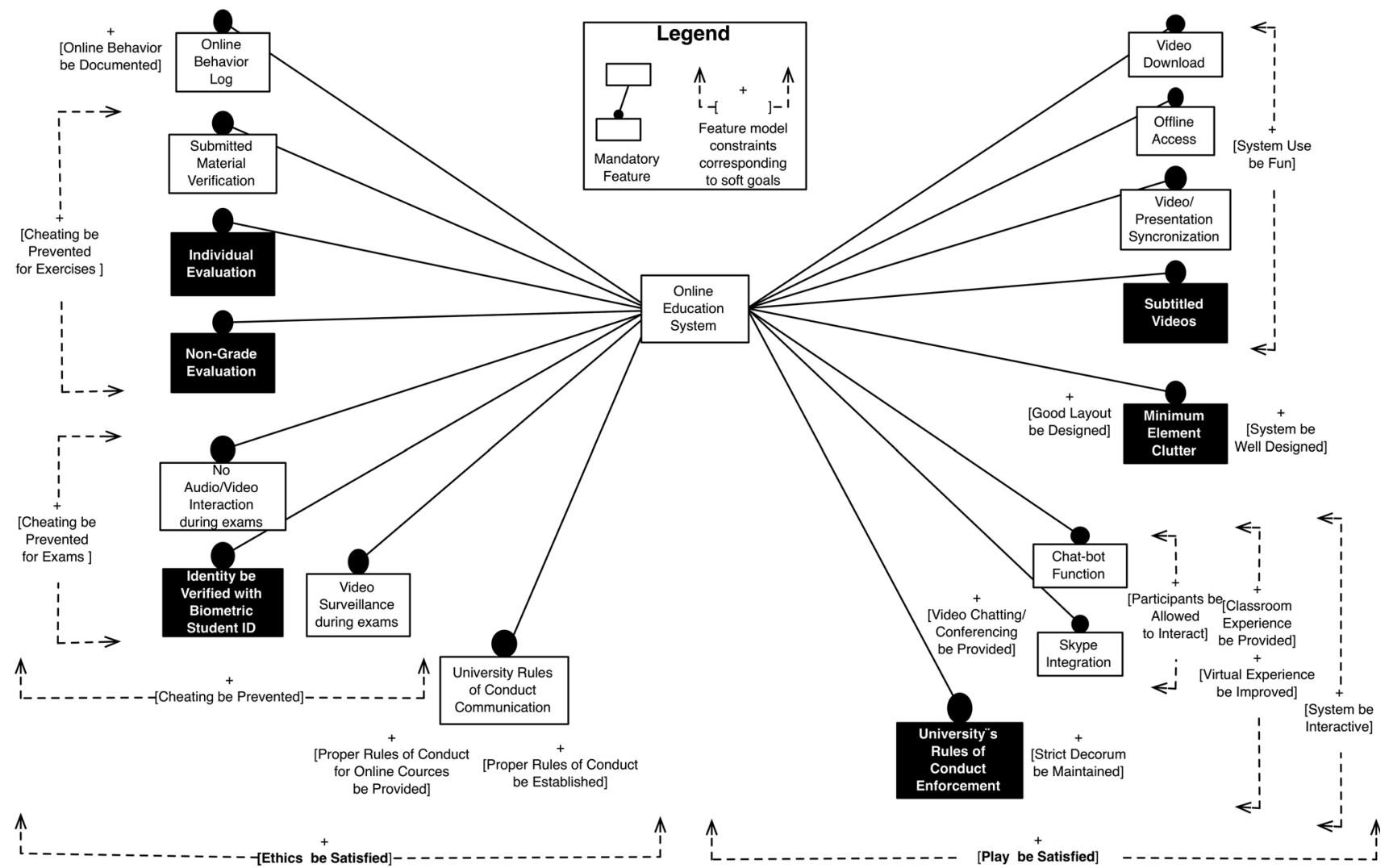

Fig. 7 Feature model for the product configuration for Non-Master's Students. Non-shaded features are common to both segments; darkly shaded features denote the functionality required by this consumer segment

shaded (Fig. 7), features derived from goals unique to Masters Students are lightly shaded (Fig. 8), and features derived from goals common to both segments are nonshaded (Figs. 7, 8).

The features identified for Non-Master students in Fig. 7 will be further used as the source for deriving low-level requirements for developing the online education product configuration for this consumer segment, while the features identified in Fig. 8 for Master students will be part of the other product configuration. To repeat, the choice of the products in the product line is done in Step 1 of the method by segmenting the consumers' population using demographics and context of use in a desired way-according to the organization's goals, to foster the grouping of dominant differences regarding the preferences, or in some other way. In Step 2, the selected products are configured with user specific features, using goal modeling.

Transforming the obtained feature models to the system requirements artifacts modeled with Use Cases involves the following activities:

For common features across the feature models, Use Cases are elicited from a common feature by creating a corresponding Use Case Diagram and further documenting the interactions for each Use Case. The obtained requirements artifacts are valid for the entire product line and labeled as common, i.e., they complement the core functional modules of the line. The stakeholders involved in the elicitation of the use cases could be domain experts, and/or the representatives from the consumer segments. For instance, "Submitted Material Verification" (see the feature in Figs. 7, 8) will be used to derive the Use Cases to, for instance, choose a verification method, perform the verification, and present the outcome.

For those features specific to one or more product, configurations are transformed to Use Cases similarly to the previous alternative; however, apart from the domain experts, the consumer stakeholders are chosen from the segments requiring the features. The obtained requirements artifacts represent variability in the line and must be labeled accordingly, i.e., to complement the core and common functionalities for the products containing those features. An example of a feature specific to a product is "Subtitled Videos" in Fig. 7.

In addition to the above guidelines, it is needed to decide how the alternative and conflicting preferences will be handled in the process, when such are elicited during the goal modeling. Both behaviors may be found in a single 


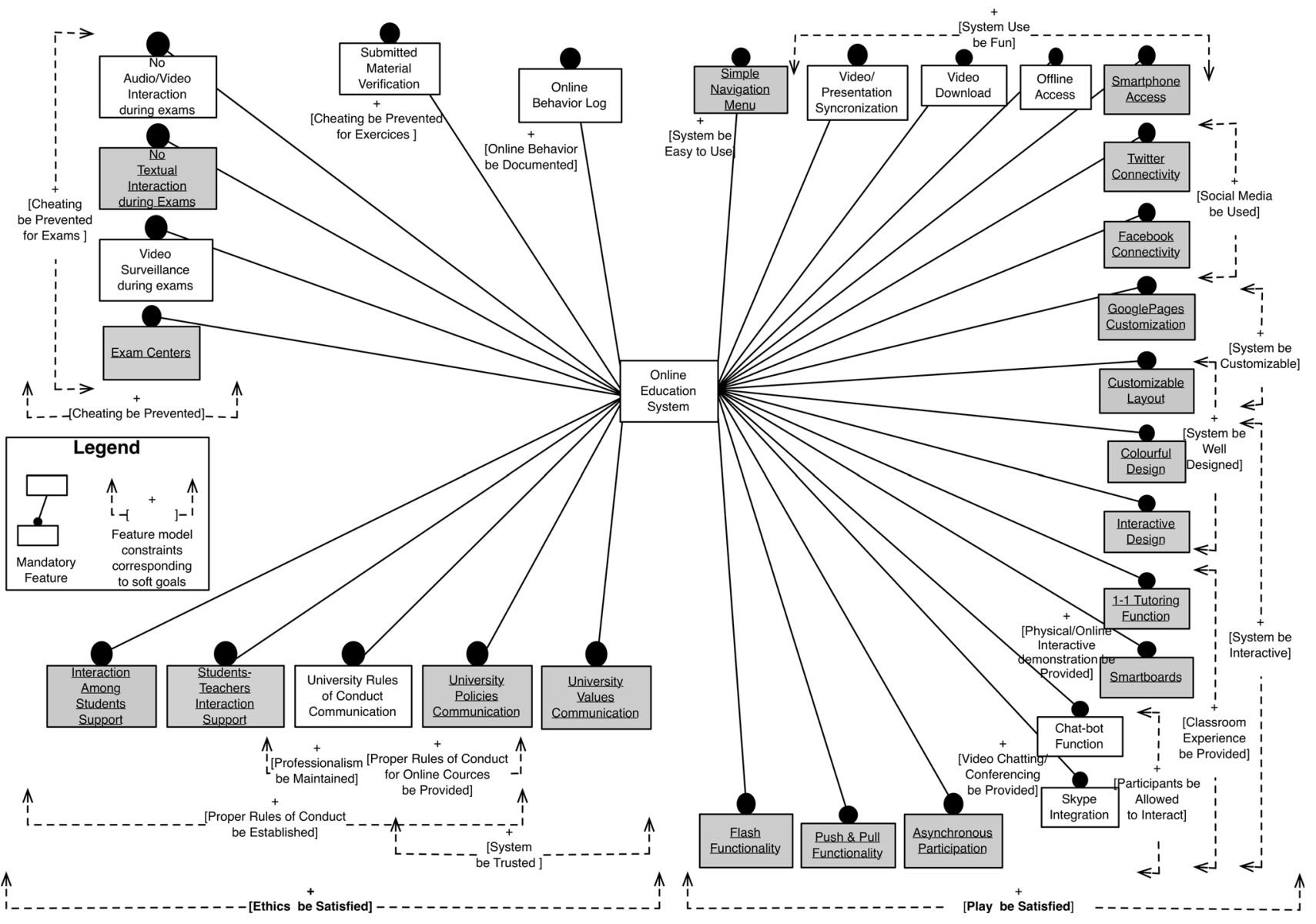

Fig. 8 Feature model for the product configuration for Master's Students. Non-shaded features are common to both segments; lightly shaded features denote the functionality required by this consumer segment

segment (product) and can either be resolved based on the organizational preferences in the goal models itself or upon feature modeling, i.e., when documenting Use Cases for development.

Apart from the qualitative measures of Consumer Values used in Step 2 to elicit the intentions and the features for different product configurations in the line, the quantitative measures of Basic Values enable setting the rankings on the qualitative ones to use them as prioritizations in the development of products. To repeat, Schwartz's theory defines values as desirable, trans-situational goals, varying in importance, that serve as guiding principles in peoples' lives. The ranking of these values via the PVQ (see Sect. 3.2) is an important aspect of how they can be utilized within this method for the prioritization of system features discovered during requirements elicitation. Below a description of one possible method for accomplishing this is shown.

The Kano model [45] was developed to categorize the attributes of a product or service, based on how well they are able to satisfy customers' needs. Eliminating problems and failures can be linked to expected (basic) requirements. Figure 9 illustrates the Kano model.

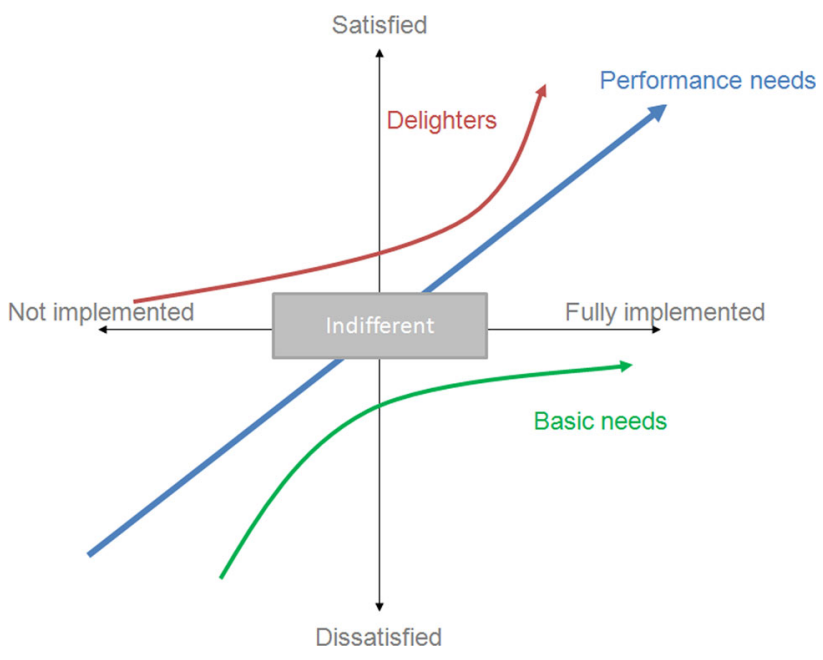

Fig. 9 Kano's model of customer satisfaction [45]

"Basic" (i.e., must-be or expected) attributes are those requirements which often go unnoticed by most customers, since customers expect these requirements to be met in the product or service [44], but their absence is very 
dissatisfying. "Performance Needs" (i.e., "One-dimensional") attributes are also termed "more is better" but could also be "faster is better" or "easier is better". "Delighter" (i.e., "Attractive") attributes are beyond customers' expectations. Their absence does not dissatisfy customers but rather their presence excites them. Each in turn has a measure of success: Threshold, Performance, and Excitement Attributes, respectively. These categories are discovered through qualitative analysis of customer requirements, where an evaluation table is created containing data for each of the attributes described above. Customers complete the table to rank those requirements, which populate the model as shown in Fig. 9.

Numerous quantitative extensions to Kano have been proposed within the field of satisfaction and customer requirements (S-CR) among them [46-48]. For example, Matzler et al. [49] propose the development of a questionnaire that relates the specific needs that the product and features under consideration must address to engage a customer. While this does not directly address values as understood by Schwartz, it could be easily appropriated for the purposes of the present method.

Recalling the description of the PVQ in Sect. 3.2, Schwartz's values include a division between positive and negative values, where positive associations shift to more negative associations. This can be considered as the inflection point at Performance Needs, whereupon either Delighters or Basic Needs can be addressed. Lower weights, which indicate a high degree of connectedness to a value, indicate in Schwartz a higher affinity to that value, and when applied to the current process, a higher priority. Using this inflection point, values of $1-3$ or higher are granted a higher priority than those greater 4-6. A second refinement is possible within the sub-areas of the model in which the same values provided by Schwartz are utilized for additional prioritization (see Sect. 6, Preference Capture). Finally, CPMM can be directly applied to Kano [45] for additional refinement. For example, the Basic Requirements, described as implied, self-evident, and taken for granted [49] are identical to those of Maslow's Physiological Needs as shown in Sect. 3.1.

\section{Analysis of results}

In the following, we discuss an overall quality of the presented method, followed by an analysis of the results in preference capture and goal/feature modeling method steps.

The presented work directly addresses the underresearched area within the development of information systems that utilize user values, thereby better aligning them with the businesses that they are intended to support.
As argued in the introduction of this study, given their importance within business-IT alignment, user values are neither captured nor formalized sufficiently within current design approaches to IT system development. The work utilizes research from the areas of psychology, operations research, and requirements engineering to find a way to solve this problem. As a solution, we propose a conceptualization in the form of the Consumer Preference MetaModel (CPMM) which is used to capture the values of users, as well as to capture variability among them, further used by the instrument of SPL to develop products accommodated to the values. Contrasted to well-established works on deriving the requirements for SPL, our method's novelty comes by eliciting the products of the line, as well as their configurations, upon user values.

The method has been evaluated in terms of feasibility through its application to a real case. The case has illustrated the feasibility of deriving features of products in a SPL (online education system) from consumer preferences (sample population of students from around the world interested in studying in Sweden). Moreover, the method, along with the encompassing techniques and artifacts, has been also verified; data captured from users have been used to instantiate CPMM as specified by the model itself. Both the goal modeling and feature modeling techniques used, $i^{*}$ [34] and FODA [35], respectively, have been applied in accordance to their notations' grammar.

\subsection{Preference capture}

CPMM is designed to house different user value frameworks. It is considered that any such framework, in addition to its top-level value classification (archetypes), provides assessment of its archetypes in either qualitative or quantitative form; we named them Measures in CPMM.

Currently, User Needs, Basic Values, and Consumer Value frameworks are included in the meta-model (Fig. 2). Through the use of Schwartz's Basic Values framework, we gain a deep understanding about what peoples' values are, but we do not know how to activate or fulfill them. Thus, utilizing a consumer values framework, such as Holbrook's, is crucial for understanding how to develop software solutions that will engage those more closely held values of Schwartz. Because Schwartz does not have this more consumer orientation, the need to supplement it with an activating agent, such as Holbrook, is needed. However, within the meta-model we propose, an alternate framework such as ServQUAL [51] could be utilized for service-oriented environments, as it already contains a consumer orientation. We would argue that such a choice loses the richness of the profiles that Schwartz provides, but it is perfectly conceivable for such a solution to be offered. 
In this study, it has been demonstrated how the Basic Values of Schwartz could be utilized to obtain the rankings of generic preferences of Non-Master and Master user segments (such as Universalism or Power) and then the mapping of the results to the qualitative values specific to a concrete product, namely Consumer Values of Holbrook, to integrate the measurement instruments of both, thus obtaining the values to be developed, as well their rankings. The empirical results have shown substantial differences in the qualitative assessments of values as given by Non-Master and Master students (Figs. 5, 6), while for the quantitative, "Play" has been the highest ranked for Master, and "Ethics" for Non-Master; the other rankings though have been quite similar (Fig. 3). The choice of the segmentation Non-Master/Master has been based upon strategic goals of a higher education organization in Sweden for which the study has been performed; however, the segmentation provided in CPMM could effectively be used to discover and then utilize the preferences targeting some other strategy, such as "Increase distance course offerings globally".

Thereby we have analyzed Domestic and International consumer segments from the surveyed population to assess their preferences and the rankings among them. At the highest level, segmenting the population between Domestic and International yields differences between the priorities of five values-Achievement, Benevolence, Conformity, Self-Determination, and Universalism - that would be significant enough to shift their value categories in the Domestic population were they segmented differently, e.g., Non-Master's and Master's students. Further refining of these larger cohorts with the Domestic subpopulation "Applied to an advanced level program with Swedish ID" and the International subpopulation "Applied to an advanced level program without Swedish ID," distinctive differences in both their priority and their category were found in Schwartz's Basic Values. These differences included relative priority for each subpopulation as well as their weight. For example,

the top rated value for Domestic applicants was Benevolence and

the top rated value for International applicants was SelfDetermination.

This difference places Self-Determination as Domestic applicants' third most important value, shifting the ranking of their value portraits from 1-2 ("Very much like me") to 2-3 ("Like me"). Similarly, the fourth highest ranked value for Domestic applicants-Hedonism differed from the fourth highest ranked value for International applicants, Achievement. Additionally, Achievement had the most significant difference in weight between the two subpopulations, with Domestic rated at 2.69/Like me and 1.90/
Very much like me. This nearly changes the value rankings of the two populations: Domestic to "Somewhat like me" and International to "Like me".

Finally, to provide a micro-segment, the Domestic subpopulation "People with Swedish ID applied to a program in advanced level at Stockholm University" rated the value Conformity at $3.47 /$ Somewhat like me. There is a .92 point difference between this and the International subpopulation "People applied to a program in advanced level at an university and with qualifications from a country other than Sweden" at 2.55/Like me. This difference is significant enough to change the value ranking were the segmentation to occur differently, e.g., Non-Master and Master.

Applying the same Domestic/International distinction to the qualitative study's population yielded similar results, where Domestic applicants had a lower interest in the value Conformity (3.6/Somewhat like me) than International applicants, who rated it as $2.65 /$ Like me. Other values with a difference that was larger than .5 were Benevolence (Domestic 2.50/Like me and International 1.71/Very much like me and Security (Domestic 3.40/Like) and International (2.65/Like me). In only 2 of the 10 values-Hedonism and Power-did Domestic and International students have a negligible difference between how they ranked those values.

\subsection{Goal and feature modeling}

While in this instance of the method $i^{*}$ has been used for goal derivation from consumer preferences, other goal modeling techniques can also be used, from simple goal models to techniques such as Tropos [39], KAOS [40]. For example, Yu et al. [11] use simple goal models to derive features while implementing their proposal in a tool using $i^{*}$. An issue of concern relevant across goal modeling techniques, and modeling in general, is the scalability of such model-dependent efforts. Very often such models become unwieldy and maintaining them becomes a cumbersome task. Our example presented two partial SR diagrams focused on the top two consumer values (Ethics and Play) of the user segments defined for the online education system. Thus, the complete SR diagram for all consumer values can be anticipated to be very large. Additionally, considering the fact that this goal derivation from consumer preferences takes place in support of/relation to the intentional elements of a system's core functionality, it becomes clear that efforts on internal evaluation of the SR diagram, as well as its maintenance and use are non-trivial efforts, especially with the lack of supporting tools.

Features are commonly reorganized when finalizing the feature model allowing for a more accurate identification of variability points resulting concrete products from the SPL. 
However, in our approach, variability is determined by segments of CPMM prior to feature derivation. Reorganization takes place during goal derivation, as indicated by Guideline 3 (Sect. 5.1), where goals and soft-goals derived from the quality measures of CPMM are grouped with respect to the intentional elements directly contributing to the consumer value soft-goals. Despite the fact that in our method, variability of features are predefined when deriving feature models, reorganization of features is still relevant but for a different reason. When alternative options are expressed within a segment, these are derived as alternatives in the feature model offering different setups of the same product in the SPL. While this type of variability does not influence the selection of products in the SPL, it is useful in deciding on the alternative chosen to facilitate the particular segment for which the product is defined (e.g., alternative selection due to costs).

\section{Conclusion}

We have proposed to elicit requirements for software product lines by modeling values of consumers as a starting point. The presented consumer value-aware requirements framework consists of a value-based Consumer Preference Meta-Model (CPMM), and a method for its use to capture preferences of consumers for a product, and for their further mapping to goal and feature models to configure requirements for SPL. The usability of the method in this paper has been assessed empirically for an online education system in higher education, whereas in other our studies we have also analyzed it in real-world cases from health, sales, and telecom services. In each of these sectors, "consumer sensing" is greatly important-either to increase the usability of a product by a significant group of consumers, or to preserve the use of the product in businesses where low profit margins and easy switching by consumers make for extremely competitive environments.

Modeling consumer preferences using CPMM utilized several user value frameworks. The value theory of Schwartz has been used particularly for eliciting the importance of the universal values relative to each other, while Holbrook's framework allows for gathering of consumer values. The two frameworks have been integrated with a proposed set of mappings to facilitate an integrated method to identify and prioritize the consumer's preferences about a product, including the capability to segment this according to consumer demographics and diverse contexts of use of the product. The outcome is an integrated consumer value-aware framework spanning both elicitation and classification of the values applicable to any line of business. As it has been emphasized in the previous section, being built as a generic business model, CPMM is extendable to include other relevant user value frameworks that could emerge, thus constituting the model relevant to any kind of preference type entailed.

Transforming consumer preferences to an RE framework, in particular $\mathrm{i}^{*}$, has been proposed as a way to complement the modeling of the core functional goals for a software system, with the outcome from the mappings of the elements of CPMM to those in $i^{*}$. The information on the importance of consumer values, as well as the classification of different consumers groups sharing similar preferences, have been also included in the goal modeling, thus enabling a creation of feature models, where the features are already classified to capture the configurations of different products in a software line.

We believe that the presented research will contribute to systematic development of the quality requirements for a system, as well as to the emergence of new configurations of software products and services.

Open Access This article is distributed under the terms of the Creative Commons Attribution License which permits any use, distribution, and reproduction in any medium, provided the original author(s) and the source are credited.

\section{References}

1. Pohl K, Böckle G, van der Linden F (2005) Software product line engineering: foundations, principles, and techniques. Springer ISBN:3540243720

2. Krueger C (2006) New methods in software product line practice. Commun ACM 12:37-40

3. Software Product Lines. Tool Vendors. http://www.softwareproductlines.com/resources/vendors.html, last accessed 2013-01-20

4. Geerts G, McCarthy WE (2002) An ontological analysis of the primitives of the extended-REA enterprise information architecture. Int J Account Inf Syst 3:1-16

5. Gordijn van Eck J and Wieringa R (2009) Requirements engineering techniques for e-Services. In: Service-oriented computing. cooperative information systems series. The MIT Press, Cambridge, pp 331-352. ISBN:9780262072960

6. Osterwalder A, and Pigneur Y (2010) Business model generation: a handbook for visionaries, game changers, and challengers. Wiley, ISBN: 9780470876411

7. Kotler P (1991) Marketing management, 7th edn. Prentice-Hall, Englewood Cliffs, NJ

8. Kaplan R and Norton D (2004) Strategy maps: converting intangible assets into tangible outcomes. Harvard Business Review Press, ISBN: 1591391342

9. Wikipedia, the free encyclopedia. Electronic Health Record, http://en.wikipedia.org/wiki/Electronic_health_record, last accessed 2013-01-09

10. Mylopoulos J, Chung L, Liao S, Wang H, Yu E (2001) Exploring alternatives during requirements analysis. J IEEE Softw 18(1):92-96

11. Yu Y, Lapouchnian A, Sampaio do JC and Mylopoulos J (2008) Configuring features with stakeholder goals. In: Proceedings of the ACM symposium on applied computing (SAC), pp 645-649

12. Batista T, Bastarrica M, Soares S and Fernandes L (2008) A marriage of MDD and early aspects in software product line 
development. In: Early aspects workshop at 12th international software product line conference (SPLC'08), pp 97-104

13. Silva C, Alencar F, Araújo J, Moreira A and Castro J (2008) Tailoring an aspectual goal-oriented approach to model features. In: Proceedings of the 20th international conference on software engineering and knowledge engineering (SEKE'08), pp 472-477

14. Yu E (1995) Models for supporting the redesign of organizational work. In: Proceedings of the conference on organizational computing systems (COOCS 1995). ACM press, Milpitas, California, USA, pp 226-236

15. Gordijn J, Akkermans JM and van Vliet JC (2000) Business modeling is not process modeling, conceptual modeling for e-business and the web, LNCS 1921. Springer, pp 40-51

16. Weigand H, Johannesson P, Andersson B, Bergholtz M, Edirisuriya A, Ilayperuma T (2006) On the notion of value object. In: Proceedings of advanced information systems engineering: 18th international conference (CAiSE06), Springer 4001, pp 321-335

17. Ilayperuma $T$ and Zdravkovic $J$ (2010) Exploring the value-based business models from the inter-organizational collaboration perspective. In: Proceedings of the 25th ACM symposium on applied computing (SAC), ISBN: 978-1-60558-639-7

18. Powell-Mantel S, Kardes FJ (1999) The role of direction of comparison, attribute-based processing, and attitude-based processing in consumer preference. J Consum Res 25:335-352

19. Maslow A (1954) Motivation and personality. Harper, New York. ISBN 0060419873

20. Schwartz S (1992) Universals in the content and structure of values: theory and empirical tests in 20 countries. In: Zanna M (eds) Advances in experimental social psychology, vol 25. Academic Press, New York, pp 1-65

21. Holbrook MB (1998) Consumer value: a framework for analysis and research. Routledge, London, GBR

22. Rokeach M (1973) The nature of human values. Free Press, New York

23. Schwartz SH (2005) Basic human values: their content and structure across countries. In: Tamayo A, Porto JB (eds) Values and behavior in organizations. Vozes, Petrópolis, pp 21-55

24. Epstein M, Manzoni J-F (1998) Implementing corporate strategy: from Tableaux de Bord to balanced scorecards. Eur Manag J 16(2):190-203

25. Svee EO, Giannoulis C, and Zdravkovic J (2012) Towards consumer preference-aware requirements. In: Bajec $\mathrm{M}$ and Eder $\mathrm{J}$ (eds) CAiSE 2012 Workshops, LNBIP 112, pp 531-542

26. Dey A (2001) Understanding and using context. Pers Ubiquit Comput 5(1):4-7

27. Hérvas R, Bravo J and Fontecha J (2010) A context model based on ontological languages: a proposal for information visualisation. J. Univers Comput Sci (J UCS) 16(1):1539-1555

28. Svee EO, Giannoulis C, Zdravkovic J (2011) Modeling business strategy: a consumer value perspective, proceedings of practice of enterprise modeling (PoEM 2011). LNBIP 92:67-81

29. Svee EO, Zdravkovic J, and Giannoulis C (2012) Consumer value-aware enterprise architecture. In: Cusumano MA, Iyer B, and Venkatraman N (eds) (ICSOB 2012), LNBIP 114, 55-69

30. McCleskey J (2009) Five strategies to enhance learner motivation in e-learning design learning solutions e-magazine, August 10

31. Smith R (2008) Motivational factors in e-learning. June 26, 2008. George Washington University. http://www.ruthcsmith.com/ GWU\%20Papers/Motivation.pdf, last accessed 2012-12-06

32. van der Raadt B, Gordijn J, Yu E (2005) Exploring web services ideas from a business value perspective. In: Atlee J, Roland C (eds) Proceedings of the 2005 13th IEEE international conference on requirements engineering (RE05). C. IEEE Computer Society, Los Alamitos, pp 53-62
33. Andersson B, Johannesson P and Zdravkovic J (2009) Aligning goals and services through goal and business modeling. The international journal of information systems and e-business management (ISEB), Special issue on design and management of business models and processes in services science, Springer, vol 7, pp 143-169

34. i* Wiki, http://istar.rwth-aachen.de/tiki-view_articles.php, last accessed 2013-02-01

35. Kang KC, Cohen SG, Hess JA, Novak WE, Peterson AS (1990) Feature-oriented domain analysis (FODA) feasibility study, Technical report No. CMU/SEI-90-TR-21. Software Engineering Institute, Carnegie Mellon University, Pittsburgh, PA

36. Czarnecki K, Helsen S, and Eisenecker UW (2004) Staged configuration using feature models. In: Proceedings of SPLC 2004, pp 266-283

37. Silva C, Borba C and Castro J (2011) A goal oriented approach to identify and configure feature models for software product lines. In: Proceedings of the WER'11, Rio de Janeiro, Brazil

38. Grau G, Franch X, Maiden N (2008) PRiM: An i*-based process reengineering method for information systems specification. Inf Softw Technol 50(1-2):76-100

39. Bresciani P, Perini A, Giorgini P, Giunchiglia F, Mylopoulos J (2004) Tropos: an agent-oriented software development methodology. Auton Agent Multi-Agent Syst 8(3):203-236

40. van Lamsweerde A (2001) Goal-oriented requirements engineering: a guided tour. In: 5th IEEE international symposium on requirements engineering. IEEE Press, New York, pp 249-262

41. Schwartz S, Melech G, Lehmann A, Burgess S, Harris M, Owens V (2001) Extending the cross-cultural validity of the theory of basic human values with a different method of measurement. J Cross Cult Psychol 32:519-542

42. European Social Survey Education Net, "Chapter 4, Measuring Values-ESS EduNet” http://essedunet.nsd.uib.no/cms/topics/1/4/, Accessed February 5, 2013

43. Norwegian Social Science Data Services. (n.d.). European social survey (ESS) data, round 5. Retrieved January 25, 2013, from http://ess.uib.no/ess/round5/

44. Lim PC, Tang NK, Jackson PM (1999) An innovative framework for health care performance measurement. Manag Serv Quality 9(6):423-433

45. Kano N, Seraku N, Takahashi F, Tsuji S (1984) Attractive quality and must-be quality. J Jpn Soc Quality Control 14(2):39-48

46. Wang T, Ping J (2010) Understanding customer needs through quantitative analysis of Kano's model. Int J Quality Reliab Manag 27(2): 173-184

47. Xu Q, Jiao RJ, Yang X, Helander M, Khalid HM, Opperud A (2009) An analytical Kano model for customer needs analysis. Des Stud 30(1):87-110

48. Chen CC, Chuang MC (2008) Integrating the Kano model into a robust design approach to enhance customer satisfaction with product design. Int J Prod Econ 114(2):667-681

49. Matzler K, Hinterhuber HH (1998) How to make product development projects more successful by integrating Kano's model of customer satisfaction into quality function deployment. Technovation 18(1):25-38

50. Liaskos S, McIlraith S, Sohrabi S, Mylopoulos J (2011) Representing and reasoning about preferences in requirements engineering. Requir Eng J 16(3):227-249. doi:10.1007/s00766-0110129-9

51. Parasuraman A, Zeithaml VA, Berry LL (1988) Servqual. J Retail 64(1):12-37 